\title{
Competência em informação como forma de pedagogia decolonial e intercultural: construindo significados
}

\author{
Information literacy as a form of decolonial and \\ intercultural pedagogy: building meanings
}

Guilherme Goulart Righetto a,*

Cezar Karpinski a $\mathbb{1 1}$

Elizete Vieira Vitorino a (D)

RESUMO: A competência em informação diz respeito, em síntese, à aprendizagem contínua, sendo uma forma de autoconsciência, socialização autoguiada ou de autodenominação. É uma ferramenta que pode levar ao empoderamento, à autoexpressão e ao diálogo intercultural dos cidadãos. No entanto, dependendo da natureza do terreno social, a competência em informação pode servir a propósitos distintos dos que se esperam em sua função social. Isso porque, ao considerar a informação como mecanismo de poder, podem-se constituir práticas opressivas ou libertadoras às minorias sociais, em especial às populações latino-americanas, considerando suas diversidades culturais, sociais e históricas. $O$ objetivo geral do artigo, dito isto, é apresentar os pressupostos teóricos para a construção de uma competência em informação "subversiva" aos padrões hegemônicos colonizadores, respaldado pela pedagogia decolonial e pela interculturalidade, buscando, assim, responder a seguinte questão: quais pressupostos são necessários para a edificação de uma competência em informação "subversiva"? Metodologicamente, a pesquisa que resultou neste artigo é exploratória, qualitativa e bibliográfica, com cunho ensaístico. O principal resultado se pauta na ratificação do fazer a competência em informação como fazeres-outros, expandindo as formas de discutir, de ensinar e de assimilar as múltiplas formas possíveis dessa metacompetência. Conclui-se que é preciso assumir tal competência como metodologia(s) e ação(es) emergente(s) em contextos de marginalização, subalternização, luta, reexistência e resistência, contribuindo com práticas insurgentes de resistir, (re)existir e (re)viver, que possibilitam modos muito diversos de ser, existir, pensar, conhecer, sentir, ser e conviver - ou seja, como práxis fronteiriça que afronta a colonialidade do poder e as suas práticas pedagógicas.

Palavras-chave: Competência em Informação; Pensamento Decolonial; Pedagogia Decolonial; Interculturalidade.

\begin{abstract}
Information literacy refers, in summary, to continuous learning, being a form of selfawareness, self-guided socialization or self-denomination. It is a tool that can lead to citizens' empowerment, self-expression and intercultural dialogue. However, depending on the nature of the social terrain, such literacy can serve purposes different from those expected in its social function. The general objective of the article is to present the theoretical assumptions for the construction of a "subversive" information literacy to the colonizing hegemonic standards, supported by decolonial pedagogy and interculturality, thus seeking to answer the following question: which assumptions are necessary for building a "subversive" information literacy? Methodologically, the research that resulted in this article is exploratory, qualitative and bibliographic, with an essayistic nature. The main result is based on the ratification of making information literacy as do-others, expanding the ways of discussing, teaching and assimilating the multiple possible forms of this metaliteracy. It is concluded that it is necessary to assume such literacy as methodology(s) and emerging action(s) in contexts of marginalization, subordination, struggle, reexistence and resistance, contributing to insurgent practices of resisting, (re)existing and (re)living, which make possible very different ways of being, existing,
\end{abstract}

a Departamento de Ciência da Informação, Universidade Federal de Santa Catarina, Florianópolis, SC, Brasil.

*Correspondência para/Correspondence to: Guilherme Goulart Righetto. E-mail: rghtto@gmail.com.

Recebido em/Received: 25/06/2021; Aprovado em/Approved: 20/09/2021.

Artigo publicado em acesso aberto sob licença CC BY 4.0 Internacional $@(1)$ 
thinking, knowing, feeling, being and living together - that is, as borderline praxis that affront the coloniality of power and its pedagogical practices.

Keywords: Information Literacy; Decolonial Thinking; Decolonial Pedagogy; Interculturality.

\section{INTRODUÇÃO}

Existe uma noção lugar-comum nas áreas da Biblioteconomia e da Ciência da Informação de que o desenvolvimento da competência em informação é inerentemente algo totalmente necessário e deveras benéfico, tanto para as pessoas que se deseja instruir quanto para as áreas citadas como um todo. Todavia, além da consideração das consequências benéficas do desenvolvimento dessa competência, como a adoção ou internalização de um conjunto de técnicas ou ferramentas mentais, é igualmente importante considerar seus contextos de inserção social (Luyt; Azura, 2014).

Nesse rol, entende-se que ela não deve mais ser negligenciada por governos e formuladores de políticas públicas, - locais, regionais e/ou mundiais - dado o robusto corpo emergente de literatura acadêmica que apoia a sua relevância na atualidade. Trata-se de um assunto necessário de aprendizagem contínua, sendo uma forma de autoconsciência, socialização autoguiada ou de autodenominação. É uma ferramenta que pode, em última instância, levar ao empoderamento, à autoexpressão e ao diálogo intercultural dos cidadãos. (Dantas, 2012).

Ademais, empoderar é um verbo que conota ação e poder. $O$ indivíduo associado a essa ação torna-se agente ativo nos processos que envolvem o estabelecimento de vínculos com outros indivíduos, de modo que ele se expresse e demande suas reivindicações a partir de uma perspectiva crítica de seu cotidiano e suas necessidades. A autoexpressão, por sua vez, aqui é vista como o entendimento das perspectivas múltiplas de mundo, e à valorização pessoal, no que diz respeito à atuação sociopolítica, em termos de crítica e de luta-resistência. E o diálogo intercultural é proposto a partir da superação da concepção de cultura como algo estático, de entidades encerradas em si mesmas. Aponta-se para a permeabilidade das fronteiras culturais e o potencial criativo que os indivíduos nelas exercem. A permeabilidade é indicada quando, mesmo em situação assimétrica, como em casos extremos, a cultura dita majoritária-dominante ainda assim sofre influências da cultura subjugada. (Dantas, 2012). 
Isto posto, e dependendo da natureza do terreno social, a competência em informação pode servir a propósitos distintos dos que se esperam em sua função social. Isso porque, ao considerar a informação como mecanismo de poder, podem-se constituir práticas opressivas ou libertadoras às minorias sociais, em especial às populações latino-americanas, considerando suas diversidades culturais, sociais e históricas.

Nesse sentido, o desenvolvimento da competência em informação deve e pode servir como um movimento político-social, reivindicando o uso de seus preceitos como exercício democrático e diplomático (Vitorino; Piantola, 2019; Latour, 2004). Além disso, se espera que o resultado de seu desenvolvimento seja uma prática simétrica de diálogo, redefinindo a civilização - ou melhor, as civilizações - como expansão de fronteiras, ampliação de redes e proliferação de vozes (Miglievich-Ribeiro, 2014). Acrescenta-se ainda a possibilidade de a competência em informação atuar em prol de uma prática decolonial, a partir da articulação dos saberes e fazeres locais silenciados por formas hegemônicas de poder, especialmente as de caráter colonialista.

Ademais, a crítica decolonial deslinda uma face ocultada na modernidade, a colonialidade, e convida à conversação os conhecimentos produzidos nas bordas da globalização hegemônica, algo sem paralelo até então. Sobretudo, os estudos decoloniais explicitam que os erros da modernidade vitoriosa nunca foram efeitos imprevistos, indesejáveis, produtos precoces da incompletude do projeto moderno, mas seus elementos intrínsecos. Combatem assim, na diversidade das correntes e abordagens, qualquer crença fundamentalista na universalidade totalitária.

O objetivo geral do artigo, dito isto, é apresentar os pressupostos teóricos para a construção de uma competência em informação "subversiva" aos padrões hegemônicos colonizadores, respaldado pela pedagogia decolonial e pela interculturalidade, buscando, assim, responder a seguinte questão: quais pressupostos são necessários para a edificação de uma competência em informação "subversiva"?

Por pedagogia decolonial, entende-se uma prática educativa antirracista e promotora de discussões sobre vertentes históricas, epistêmicas e comportamentais distintas à lógica dominante eurocêntrica (Oliveira; Candau, 2010). Já a interculturalidade, ao contrário do multiculturalismo que pressupõe a existência de uma cultura dominante que aceita, tolera ou reconhece a existência de outras culturas no espaço cultural onde domina, pressupõe o reconhecimento recíproco e a disponibilidade para o 
enriquecimento mútuo entre as várias culturas que partilham um determinado espaço cultural (Santos; Menezes, 2009, p. 9).

Como aponta Hicks e Lloyd (2016), a sensibilidade em reconhecer (e repensar) os pressupostos conceituais socioculturais e ideológicos que sustentam as bases da competência em informação culminam nos reais propósitos e maneiras de como ela se desenvolve - ou de como deveria ser. Em outras palavras, o desenvolvimento dessa competência deve ser visto como plural, contextual e oposto à estandardização das culturas, vivências e formas de aprendizagens das pessoas/grupos, em especial aqueles subalternizados e vulneráveis.

\section{ASPECTOS METODOLÓGICOS}

A pesquisa que resultou neste artigo foi exploratória, qualitativa e bibliográfica, com cunho ensaístico. Exploratória porque teve como objetivo evoluir, elucidar e fazer uso de vários conceitos e ideias, a fim de formular problemas mais precisos ou hipóteses pesquisáveis para estudos posteriores. Além disso, esse tipo de pesquisa é menos rígido no planejamento e permite a investigação em diferentes mídias e fontes de informação. Por vezes, a pesquisa exploratória é a primeira etapa de uma investigação mais ampla, o que certamente se aplica aos resultados alcançados neste corpo de trabalho. (Flick, 2009).

A pesquisa qualitativa é geralmente identificada como preocupada em estudar o mundo "de fora" (Flick, 2009, p. 8), mais precisamente seus fenômenos, de forma diferente da pesquisa quantitativa, que geralmente estuda fenômenos em contextos especiais, como laboratórios. A pesquisa qualitativa analisa experiências e examina as interações que se desenvolvem em seus próprios contextos (Flick, 2009). Nas ciências sociais, este tipo de investigação se dirige a um nível de realidade não quantificada, trabalhando com o universo de significados, motivos, desejos, crenças, valores e atitudes, cujas premissas não podem ser reduzidas à mera operacionalização de variáveis (Minayo, 2001).

No âmbito da pesquisa bibliográfica, a análise se deu por meio da seleção de documentos publicados e, tendo em vista o caráter exploratório e ensaístico da proposta, os procedimentos técnicos foram direcionados para uma abordagem não probabilística, por julgamento, sendo aquela em que o pesquisador usa seu julgamento 
para selecionar o corte considerado válido para o contexto da pesquisa. (Schiffman; Kanuk, 2000). A pesquisa bibliográfica foi realizada por meio da busca de documentos e obras sobre as temáticas, e nas bases de dados Web of Science, Scopus e SciELO, onde foram selecionados 30 artigos considerados mais propícios e edificantes à discussão trazida - e entre estes, a seleção final dos artigos que trouxessem embasamento e contribuições teórico-conceituais para tal discussão.

As fontes de informação selecionadas na pesquisa referem-se à construção teórica do campo decolonial e os pressupostos considerados inerentes para a construção da competência em informação como pedagogia decolonial e intercultural, destacando aspectos teórico-conceituais envoltos, como a colonialidade do poder, a geopolítica do conhecimento, a interculturalidade e a pedagogia decolonial.

\section{BREVES APONTAMENTOS SOBRE A DECOLONIALIDADE}

Walsh (2012, 2017) e Trinidad Pérez (2012) assumem a decolonialidade ${ }^{1}$ como uma luta que enfrenta a estrutura derivada da "falha colonial". Propõe resistência e insurgência, configurando condições e possibilidades radicalmente diferentes, ou seja, decoloniais. Desse ponto de vista, a resistência oferece movimentos chamados de ações pedagógicas. São ações não só de defesa e reação, mas também de ofensa, insurgência e (re)existência circunscritas em/por uma configuração constante de uma "outra" forma de estar em/com/para o mundo. Quando se diz "outra forma", isto se refere às diferentes formas de conhecer, fazer, pensar, perceber, sentir, ser e viver em relação, que desafiam a universalidade, a lógica e a hegemonia do sistema moderno/capitalista/colonial/eurocêntrico/mundial ocidentalizado, seus fundamentos epistêmicos binários, suas concepções fragmentárias, seu antropocentrismo excessivo e suas práticas civilizatórias.

Nessa conjectura, se reconhece a "outra forma" como além das vivências nas/pelas bordas, fissuras, fronteiras e fendas do sistema mundial moderno/capitalista/colonial/eurocêntrico/ocidentalizado. Trata-se da vida caracterizada pelo influxo de práticas em constante reconfiguração, reconstituição e

\footnotetext{
1 Preferimos utilizar o termo "decolonial" e não "descolonial" pelos mesmos motivos que Walsh (2009, p. 15-16), suprimindo o "s" para marcar uma distinção com o significado de descolonizar em seu sentido clássico. Deste modo, a intenção não é desfazer o colonial ou revertê-lo, ou seja, superar o momento colonial pelo momento pós-colonial. A intenção é provocar um posicionamento contínuo de transgredir e insurgir. O decolonial implica, portanto, em uma luta contínua.
} 
remodelação, não só contra a colonialidade, mas a despeito dela. Não se trata apenas de eliminar totalmente a colonialidade, mas de viver nela/com ela sem ser afetado, sem ter que viver para ela. (Sofia, 2013; Zibechi, 2015).

O pensamento decolonial, destarte, é um pensamento que se desprende da lógica de um único mundo possível (lógica da modernidade capitalista) e se abre para uma pluralidade de vozes e caminhos. Trata-se de uma busca pelo direito à diferença e a uma abertura para um pensamento-outro. Ele se constitui em uma das variadas oposições planetárias do pensamento único (Mignolo, 2007). Trata-se também de questionar outras bases científicas, sobretudo a difundida neutralidade.

O movimento faz uma intensa crítica à modernidade e à racionalidade, que foram imaginadas, até então, como experiências e produtos exclusivamente europeus. Não se trata de rompimento, mas de reivindicar que a modernidade também é, e pode ser, fruto de todas as culturas, não apenas europeia ou ocidental. Além disso, reivindica que as ideias de novidade, avanço racional-científico, laico e secular também pode ser apropriado por outros movimentos, outros sujeitos, outros espaços. A ressignificação da modernidade é uma questão central para a libertação humana como interesse histórico da sociedade. (Suess; Silva, 2019; Mignolo, 2014).

Assim, o que o movimento decolonial busca é outra modernidade, chamada por Dussel (1995) de transmodernidade. Segundo essa proposta, a constituição do ego individual diferenciado é a novidade que ocorre com a América e é a marca da modernidade, que tem lugar não só na Europa, mas em todo o mundo que se configura a partir da América. Reconhece-se que ela representa a mudança do mundo como tal, e que o elemento básico da nova subjetividade se constitui em uma nova percepção do tempo e do espaço que permita a percepção da mudança histórica produzida pelas ações das pessoas.

À vista disso, se apreende que o reflexo do processo de colonização das Américas, especialmente na América Latina, ainda é marcante nas estruturas de poder e nos modos de ser e saber dos países desse continente. A concentração de terra, as desigualdades sociais, o novo coronelismo, o racismo, o machismo, o patriarcalismo, a imposição de ideias neoliberais e o lugar que essas nações ocuparam e ainda ocupam no sistema-mundo atual, são provas que permanecem fortes a materialidade e a subjetividade construídas pelo eurocentrismo do período colonial. Com velhas ou 
novas roupagens essas construções estão longe de romper com a essência eurocêntrica. (Mignolo, 2013; Ocaña, 2016).

Além de negros e indígenas, outros grupos sociais latino-americanos, historicamente renegados e até criminalizados, como os segregados, as mulheres, as minorias de gênero e sexualidade, os camponeses sem terra, os quilombolas, os ciganos e as comunidades tradicionais foram engrossando as parcelas dos excluídos e sendo desprezados nos processos de construção das nações latino-americanas. Nota-se que o processo de reconhecimento cultural e de autoidentificação desses grupos tem sido fundamental para a luta contra as imposições sofridas por esses coletivos (Moreira; Candau, 2007). Dessa forma, remete-se ao entendimento de que a configuração do poder, iniciada pelo colonialismo, e a configuração atual do capitalismo em nível mundial, massificam a subalternização - especialmente falando - dos grupos que perpassam a condição eurocêntrica/heteronormativa/cisgênera.

\section{COLONIALIDADE DO PODER}

Para se referir à problemática acima, Quijano (2005; 2009) propõe o conceito de colonialidade do poder. A colonialidade ${ }^{2}$ é um dos elementos constitutivos e específicos do padrão mundial do poder capitalista. Sustenta-se na imposição de uma classificação racial/étnica da população do mundo como padrão de poder e opera em cada um dos planos, meios e dimensões, materiais e subjetivos, para categorização social. Sua perspectiva origina-se e propaga-se a partir da experiência colonialista aos povos da América.

A colonialidade do poder está relacionada à ocidentalização do outro, na perspectiva da modernidade colonial, ou seja, à invasão do imaginário do outro, reconfigurando sua identidade e reorientando-a para caminhos eurocêntricos. Para Quijano (2005), a

\footnotetext{
2 "Colonialidade é um conceito diferente de - ainda que vinculado ao - colonialismo. $\mathrm{O}$ colonialismo diz respeito estritamente a uma estrutura de dominação/exploração onde o controle da autoridade política, dos recursos de produção e do trabalho de uma população determinada domina outra de diferente identidade e cujas sedes centrais estão, além disso, localizadas noutra jurisdição territorial. O colonialismo é, obviamente, mais antigo, enquanto a colonialidade vem provando, nos últimos 500 anos, ser mais profunda e duradoura que o colonialismo." (Quijano, 2009, p. 5).
} 
colonialidade do poder penetra no interior do imaginário do colonizado, distorcendo e reconfigurando as formas de conhecer, de criar conhecimento, de configurar sentido, de criar imagens, perspectivas e símbolos.

Essa noção se refere a uma episteme que constitui a identidade do colonizado, ou seja, um discurso configurado em seu mundo, a partir de sua reprodução no locus do colonizador. É este quem se encarrega de reconfigurar a realidade do colonizado por meio de sua teoria e perspectiva, que se impõem ao outro por meio de um processo epistemológico sobreposto ou imposto. Pela colonialidade do poder, o colonizador configura mal o imaginário do colonizado, nega-o, subalterniza-o e torna-o invisível, reafirmando ao mesmo tempo o seu próprio imaginário, que supostamente é o único válido. O outro, o colonizado, não é válido e, portanto, deve ser semelhante ao colonizador. (Segato, 2014; Quijano, 2009; 2014).

Nesse sentido, a colonialidade do poder constrange as formas de configurar saberes do colonizado, restringe suas constelações sígnicas, suas formas de configurar imagens e saberes, reprime seu mundo simbólico e impõe outros mundos, outros saberes, outras configurações conceituais abrangentes. Isso traz como consequência que o imaginário do colonizador se naturaliza, o outro, o colonizado, é epistemicamente subalternizado e invisível, os processos históricos não europeus que caracterizam a identidade do outro são negados e esquecidos. (Ballestrin, 2013).

A colonialidade do poder, embora pareça paradoxal, não estabelece o domínio apenas por meios coercitivos. Os europeus não reprimiram apenas fisicamente os colonizados. Em vez disso, tentaram fazê-los conceber de forma natural o imaginário cultural europeu e assumi-lo como uma forma única de se relacionar com o mundo natural, humano, social e com eles próprios. Modificaram-se radicalmente as configurações cognitivas, afetivas e volitivas do colonizado, tornando-o uma nova pessoa, feita à imagem e semelhança do ser humano no Ocidente (Castro-Gómez, 2005).

A matriz colonial de poder é, à vista disso, uma estrutura complexa de níveis interligados, conforme ilustra a Figura 1.

Figura 1. Matriz colonial do poder 


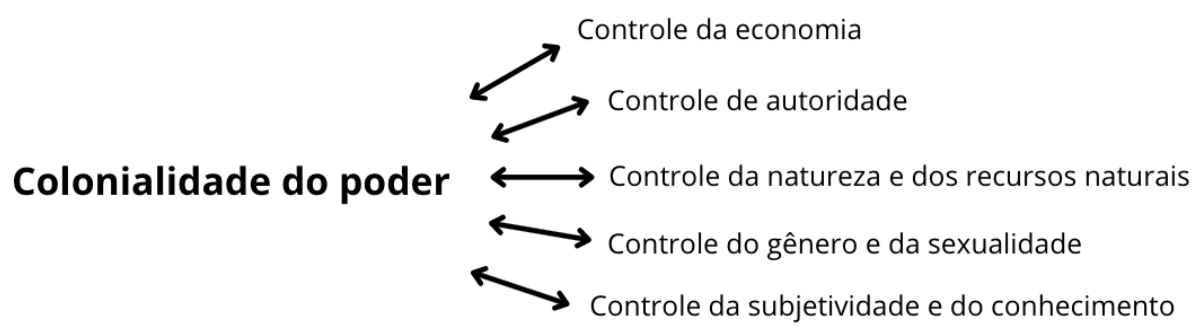

Fonte: Adaptado de Mignolo (2010).

Outrossim, a colonialidade de poder refere-se à complexa matriz ou padrão de poder sustentado pelos seguintes pilares: conhecer (epistemologia), compreender (hermenêutica) e sentir (estética). Por sua vez, o controle da economia e da autoridade (teoria política e econômica) depende das bases sobre as quais se fundamentam o conhecimento, a compreensão e o sentimento. A matriz colonial de poder é, portanto, uma rede de crenças sobre a qual a ação é posta em prática e racionalizada, aproveitada e/ou opressora por suas consequências totalitárias. (Ocaña; López; Conedo, 2018).

Logo, um dos pontos centrais da crítica de Quijano (2005; 2009; 2014) à cumplicidade entre modernidade/racionalidade é a noção exclusiva e totalitária de totalidade: tratase de uma totalidade que nega, exclui, obscurece a diferença e as possibilidades de outras totalidades. A racionalidade moderna é absorvente e, ao mesmo tempo, defensiva e exclusiva. É preciso, de forma urgente, compreender os mecanismos envoltos e destituir a matriz colonial do poder.

Destas constatações, os seguintes questionamentos surgem: como é possível iniciar esse movimento? Ou, ao menos, quais seriam as estratégias efetivas para a reconstrução e restituição de histórias silenciadas, subjetividades reprimidas, linguagens e saberes subalternizados pela ideia de totalidade definida sob o nome de modernidade e racionalidade? Em princípio, pode-se começar tal movimento propondo uma ressignificação da geopolítica do conhecimento e da interculturalidade como antídotos à colonialidade do poder e, por consequência, como pressupostos para o desenvolvimento da competência em informação como uma pedagogia decolonial e intercultural, como veremos adiante. 
A colonialidade do poder, ao mesmo tempo em que promoveu o epistemicídio colonial, criou uma espécie de fetichismo epistêmico. Isso porque a cultura, as ideias e os conhecimentos dos colonialistas aparecem de forma sedutora, que se busca imitar, impondo a colonialidade do saber sobre os não-europeus. Nesse sentido, apresenta-se uma geopolítica do conhecimento, ou seja, o poder, o saber e todas as dimensões da cultura definiram-se a partir de uma lógica de pensamento centralizado na Europa.

A geopolítica do conhecimento pode ser apreendida como a estratégia da modernidade europeia que afirmou suas teorias, seus conhecimentos e seus paradigmas como verdades universais, invisibilizando e silenciando sujeitos produtores de conhecimentos-outros. Foi esse o processo que constituiu a modernidade que não pode ser entendida sem se tomar em conta os nexos com a herança colonial e as diferenças étnicas que o poder moderno/colonial produziu (Oliveira; Candau, 2010).

A partir desse entendimento, Mignolo (2005) afirma que esse(s) processo(s), marcados por violências epistêmicas, também conduzem a uma geopolítica linguística, já que as línguas coloniais ou imperiais estabeleceram o monopólio linguístico. Cronologicamente, a línguas legitimadas foram o grego e no latim, na Antiguidade, e o italiano, o português, o castelhano, o francês, o inglês e o alemão, na modernidade. Deste modo, desprezaram-se as línguas nativas dos outros povos e, como consequência, subverteram-se ideias, imaginários e cosmovisões distintas das europeias (Oliveira; Candau, 2010).

Tal como um movimento contra-hegemônico frente às geopolíticas impostas, Mignolo (2013) destaca que o pensamento-outro caracterizado como decolonialidade se expressa na diferença colonial, isto é, em uma ressignificação da geopolítica do conhecimento em duas direções: (1) a crítica da subalternização na perspectiva dos conhecimentos invisibilizados; (2) a emergência do pensamento preambular como uma nova modalidade epistemológica na interseção da tradição ocidental e a diversidade de categorias estigmatizadas sob o ocidentalismo e o eurocentrismo.

Nesse processo, aponta-se a estratégia da interculturalidade como princípio que orienta pensamentos, ações e novos enfoques epistêmicos. O conceito de interculturalidade é central na (re)construção do pensamento-outro. A interculturalidade é concebida, nessa perspectiva, como processo e como projeto político. Para Walsh (2005), é igualmente necessária a adesão da questão do 
“posicionamento crítico de fronteira" na diferença colonial, ou seja, um processo em que o fim não é uma sociedade ideal, como abstrato universal, mas o questionamento e a transformação da colonialidade do poder, do saber e do ser. Dessa forma, se compreende que estas relações de poder não desaparecem, mas que podem ser reconstruídas ou transformadas, conformando-se de maneiras outras (Walsh, 2005).

O pensamento de fronteira significa, para Walsh (2005; 2006), tornar visíveis outras lógicas e formas de pensar, diferentes da lógica eurocêntrica dominante. 0 pensamento de fronteira se preocupa com o pensamento dominante, mantendo-o como referência e sujeitando-o ao constante questionamento e introduzindo nele outras histórias e modos de pensar. Walsh (2014) considera essa perspectiva como componente de um projeto intercultural e decolonizador, permitindo uma nova relação entre conhecimento útil e necessário na luta pela decolonização socioepistêmica.

Além disso, o pensamento crítico de fronteira permite construir variadas estratégias entre grupos e conhecimentos subalternos, como, por exemplo, indígenas, negros e LGBQTIA+ (Lésbicas, Gays, Bissexuais, Queer, Transexuais e Travestis, Intersexuais, Assexuais e todas as demais existências de gêneros e sexualidades), além do estabelecimento físico de lugares do pensamento-outro. Esses espaços, como posições críticas de fronteira, podem oferecer possibilidades de propor outros conhecimentos e aprendizados contínuos-outros por meio do diálogo crítico com os conhecimentos e modos de pensar além da colonialidade.

A dinâmica desse pensamento crítico propõe que se criem novas comunidades interpretativas que ajudem a ver o mundo de uma perspectiva-outra. Esse enfoque deve se constituir como um projeto alternativo às opressões epistêmicas e à colonialidade do ser, do saber e do poder. Walsh (2007) afirma que a proposição de uma pedagogia decolonial poderia servir no campo educativo para aprofundar os debates em torno da interculturalidade, ou seja,

[...] ao problema da "ciência" em si; isto é, a maneira através da qual a ciência, como um dos fundamentos centrais do projeto Modernidade/Colonialidade, contribuiu de forma vital ao estabelecimento e manutenção da ordem hierárquica racial, histórica e atual, na qual os brancos e especialmente os homens brancos europeus permanecem como superiores (WALSH, 2007, p. 9). 
Do ponto de vista conceitual, Walsh (2009) entende a interculturalidade como:

- Um processo dinâmico e permanente de relação, comunicação e aprendizagem contínua entre culturas em condições de respeito, legitimidade mútua, simetria e igualdade;

- Um campo de criação de novas e diversas formas de amar, ser, ser, sonhar e viver;

- Um intercâmbio que se constrói entre pessoas, conhecimentos, saberes e práticas culturalmente diferentes, buscando desenvolver um novo sentido entre elas na sua diferença;

- Um espaço de negociação e de tradução onde as desigualdades sociais, econômicas e políticas, e as relações e os conflitos de poder da sociedade não são mantidos ocultos e sim reconhecidos e confrontados;

- Uma tarefa social e política que interpela ao conjunto da sociedade, que parte de práticas e ações sociais concretas e conscientes e tenta criar modos de responsabilidade e solidariedade;

- Um projeto de vida que se configura permanentemente, uma perspectiva, um processo e não uma meta a ser cumprida.

Ainda para Walsh (2014), a interculturalidade tem um significado intimamente ligado a um projeto social, cultural, educacional, político, ético e epistêmico em direção à decolonização e à transformação. É um conceito carregado de sentido pelos movimentos sociais latino-americanos e que questiona a colonialidade do poder, do saber e do ser, também denotando outras formas de pensar e se posicionar a partir da diferença colonial, na perspectiva de um mundo mais justo.

A interculturalidade implica na compreensão de que todos os seres humanos são interculturais, versáteis e plurais. Em outras palavras, em um mundo intercultural, a definição de identidade seria um processo de autodenominação. "Isso significa que serei afro não pela cor da minha pele, mas porque assumo e aplico a cultura afro; serei mulher porque gosto de viver no matriarcado e não porque nasci mulher" (Ocaña; López; Conedo, 2018, p. 61). A identidade não é uma condição ontológica, mas epistemológica, ética, política e ideológica. (Ocaña; López; Conedo, 2018).

Por isso, a interculturalidade não deve ser analisada apenas como um simples reconhecimento do múltiplo, o que se tenta fazer na concepção do multiculturalismo, 
nem como uma tradução de projetos civilizadores, mas como o desenvolvimento sustentável das diferenças identitária, contextuais e culturais, conforme assevera Santos (2008). Para o mesmo autor, um mundo intercultural é aquele em que existem garantias e oportunidades para que todas as identidades se desenvolvam de forma sustentável.

Além do mais, a interculturalidade pode ser vislumbrada como algo inserido numa configuração conceitual que propõe um giro decolonial epistêmico capaz de produzir novos conhecimentos e outra compreensão simbólica do mundo, sem perder de vista a colonialidade do poder, do saber e do ser. Sua concepção, nessa perspectiva, representa a construção de um novo espaço epistemológico que inclui os conhecimentos subalternizados e os ocidentais, numa relação tensa, crítica e mais igualitária. (Ocaña; López; Conedo, 2018).

Sob o aspecto educacional, a interculturalidade não se restringe à inclusão de novos temas nos currículos ou nas metodologias pedagógicas, mas se situa na perspectiva da transformação estrutural e sociohistórica. A crítica intercultural defronta as formulações teóricas multiculturais que não questionam as bases ideológicas do Estado-nação que, em geral, partem de lógicas epistêmicas eurocêntricas. Essa postura “nacional” no campo educacional acaba reforçando os estereótipos e os processos coloniais de opressão e racialização, sob o pretexto de incorporar representações e culturas marginalizadas. (Oliveira; Candau, 2010; Aguero-Contreras; Urquiza-Garcia, 2016).

Em contrapartida, Walsh (2014) explica que muitas das políticas públicas educacionais latino-americanas utilizam o termo 'interculturalidade' apenas como forma de incorporar demandas. Contudo, reforçam os discursos subalternizados pelo ocidente, dentro do aparato estatal em que o padrão epistemológico eurocêntrico e colonial continua sendo o hegemônico. Ainda para Walsh (2007), a perspectiva da interculturalidade crítica é basilar para uma pedagogia decolonial:

A interculturalidade crítica [...] é uma construção de e a partir das pessoas que sofreram uma experiência histórica de submissão e subalternização. Uma proposta e um projeto político que também poderia expandir-se e abarcar uma aliança com pessoas que também buscam construir alternativas à globalização neoliberal e à racionalidade ocidental, e que lutam tanto pela transformação social como pela criação de condições de poder, saber e ser muito diferentes. Pensada desta maneira, a interculturalidade crítica não 
é um processo ou projeto étnico, nem um projeto da diferença em si [...], é um projeto de existência, de vida. (WALSH, 2007, p. 8, grifo nosso).

A perspectiva em questão é pensada a partir da ideia de uma prática política contraposta à geopolítica hegemônica do conhecimento, pois se trata de visibilizar, enfrentar e transformar as estruturas e instituições que têm como horizonte de suas práticas a lógica epistêmica ocidental, a racialização do mundo e a manutenção da colonialidade do poder. A partir dessa constatação, surge a noção de uma pedagogia decolonial, ou seja, uma prática baseada em insurgência educativa propositiva, não somente denunciativa. Nesse aspecto, o termo insurgir representa a criação e a construção de novas condições sociais, políticas, culturais e de pensamento.

Noutras palavras, é a edificação de uma noção e visão pedagógica que se projeta para além dos processos de ensino e de transmissão de saber, concebendo a pedagogia como política cultural. Segundo Walsh (2014), essa concepção tem como bases de inspiração e reflexão a obra de Paulo Freire (1996; 2013; 2014) e Frantz Fanon (1968; 2008; 2009; 2011), e está em processo de construção, tanto em teorias quanto em práticas escolares e/ou demais sistemas de aprendizagem. Nesse aspecto, por aproximações conceituais e práticas, instiga-se a analisar e discorrer sobre a competência em informação subversiva como forma de pedagogia decolonial e intercultural.

\section{COMPETÊNCIA EM INFORMAÇÃO COMO FORMA DE PEDAGOGIA DECOLONIAL E INTERCULTURAL: CONSTRUINDO SIGNIFICADOS}

Perante a realidade intercultural das sociedades latino-americanas, por exemplo, é indiscutível a necessidade de informação sobre e para as suas culturas. Apesar do crescente avanço em termos de acesso à informação, este fenômeno é questionável para aqueles que, historicamente, ainda são negligenciados e subalternizados.

O acesso à informação, assim, se relaciona diretamente com o desenvolvimento de habilidades e competências - o know-how - que permitam seu uso consciente, criativo e benéfico. A informação é, assim, o elemento constituinte da cultura de um grupo, e, em sua essência, é condição de permanência e instrumento de mudança. Por isso, o acesso à informação e ao conhecimento é tido como componente fundamental para o exercício da cidadania em contextos democráticos. Assume-se, porém, que a cidadania 
não se constrói apenas com base no acesso material à informação, mas do sujeito exige-se também compreender a capacidade de interpretação da realidade e de construção de significados.

Desse contexto, decorre o conceito de competência em informação, que vem sendo empregado mediante diversos enfoques. Se por um lado é consenso que o indivíduo competente em informação é aquele capaz de encontrar, avaliar e usar a informação eficazmente na solução de problemas e na tomada de decisão, conforme a definição da American Library Association (ALA, 1989), por outro, essa noção mostra-se limitada ao considerarmos que a própria informação comporta diversos níveis de significado e de implicação pessoal e coletiva.

Para Lloyd (2003; 2006), tornar-se competente em informação consiste em um processo holístico influenciado por relações sociais, físicas e textuais com a informação, as quais demandam uma série de práticas e atestam a complexidade e a variedade das fontes de informação dentro de um contexto. A competência em informação como uma metacompetência se constitui como uma faculdade criadora, permitindo a aquisição de novas habilidades e novos conhecimentos (Lloyd, 2003; 2006).

Nessa lógica, o conceito e o papel social da competência em informação vão alémmundo de se configurar numa simples reunião de habilidades para acessar e empregar adequadamente a informação. Trata-se de uma competência sociopolítica essencial para a construção e a manutenção de uma sociedade de pensamentos e culturasoutros, verdadeiramente democrática, em que as pessoas fazem escolhas conscientes e são capazes de determinar o curso de suas vidas. Tendo em vista essa afirmação, Jacobs (2008) observa que na medida em que a competência em informação opera dentro de um contexto sociopolítico, é também ela direcionada politicamente. Assim, ao limitar o potencial da competência em informação a normas e diretrizes, se arriscaria minimizar, quando não negar, a natureza política que lhe é inerente.

Elmborg (2006) propõe então, nessa conjuntura, para a competência em informação alternativa semelhante àquela postulada por Paulo Freire para a Pedagogia: a necessidade de desenvolver nas pessoas uma consciência crítica - a ética no sentido mais específico de refletir e posicionar-se sobre o que está dito e posto - em relação à realidade e em relação a si mesmo, centrada na colocação e solução de problemas, de modo que se possa desenvolver controle da vida e do próprio aprendizado. 
Diante disso, e como parte do pressuposto básico para viver com dignidade e responsabilidade no mundo contemporâneo, no contexto da alfabetização ao longo da vida (lifelong learning), do ponto de vista social e ético, deve-se considerar não só as prerrogativas dos desafios e exigências que as ditas "sociedades da informação e do conhecimento" apresentam (Righetto; Vitorino; Muriel-Torrado, 2018), mas também a pluralidade, a educação intercultural e decolonial - a par de atenção e do respeito pelas diversidades existentes.

Para além de sua dimensão instrumental de alfabetização contínua, a competência em informação compreende quatro dimensões que contribuem para o desenvolvimento holístico da pessoa/grupo em seu meio social: técnica, estética, ética e política. (Vitorino; Piantola, 2019). Essas dimensões servem à competência em informação em si e/ou pautada nas formas de educação decolonial e intercultural. Destarte, outras questões necessárias e envoltas ao desenvolvimento da competência em informação - em si e para ser replicada - como pedagogia decolonial e intercultural deve abranger:

- A noção de que essa competência não é um projeto colonializador/imperial/unilateral que tem um fim em si mesma, e sim, um processo intercultural e multidisciplinar que sirva como meio para um projeto de vida contínuo que propague o bem-estar, o acesso pleno à informação e a autonomia das pessoas e dos grupos, de acordo com o nível de autossatisfação dos envolvidos;

- O alargamento da competência cultural (cultural competence), isto é: estar ciente de sua própria visão de mundo; desenvolver atitudes positivas em relação às diversidades culturais; obter conhecimento de diferentes práticas culturais e visões não-hegemônicas; e desenvolver habilidades de comunicação e interação interculturais (Cooke, 2017);

- A humildade cultural (cultural humility): compromisso pessoal ao longo da vida com a autoavaliação e a autocrítica; o reconhecimento de dinâmicas e disparidades de poder; a vontade de corrigir esses desequilíbrios e de desenvolver parcerias com pessoas e grupos que defendem os outros; e a responsabilidade institucional (Tervalon; Murray-Garcia, 1998);

- A não-neutralidade ou isenção de valores e/ou contexto cultural da competência em informação, visto que a cultura é eixo estruturante para a aprendizagem plena; 
- A erradicação da disseminação da competência em informação como um conjunto de habilidades eurocêntricas, social e culturalmente hegemônicas, que emerge tradicionalmente do positivismo ocidental e de ideias econômico-racionalistas de alfabetização contínua ou como formas de conhecimento;

- O reconhecimento e a realização de ações que enfrentem os preceitos dominantes sociais, culturais e epistemológicos colonialistas imbuídos nas ideologias e metodologias utilizadas, bem como a desmistificação sobre a inferioridade da educação latino-americana;

- A noção da competência em informação como intercultural e interlinguística, ou seja, engajada com a aprendizagem e a reaprendizagem-outra contínua e contextualizada nos cenários oprimidos/subalternizados pelos projetos eurocêntricos.

Nessa incursão perspectiva, a promoção da competência em informação como projeto/pedagogia decolonial e intercultural deve, antes de tudo, "pedagogizar o descolonial e descolonizar a pedagogia", até porque tal disciplina, assim como a filosofia, a literatura, a história e a cultura ocidentais, como bem mostrou Spivak (2010; 2015), é atravessada por um passado colonialista não superado e se reconfigura em nosso presente pós-moderno/colonial (Ocaña; López; Conedo, 2018). Diante do exposto e visando ilustrar os pressupostos para a referida competência como pedagogia decolonial e intercultural, apresenta-se a Figura 2, buscando, assim, responder a questão central do estudo, isto é: quais pressupostos são necessários para a edificação de uma competência em informação "subversiva"? 
Figura 2. Pressupostos para a construção da competência em informação como pedagogia decolonial e intercultural

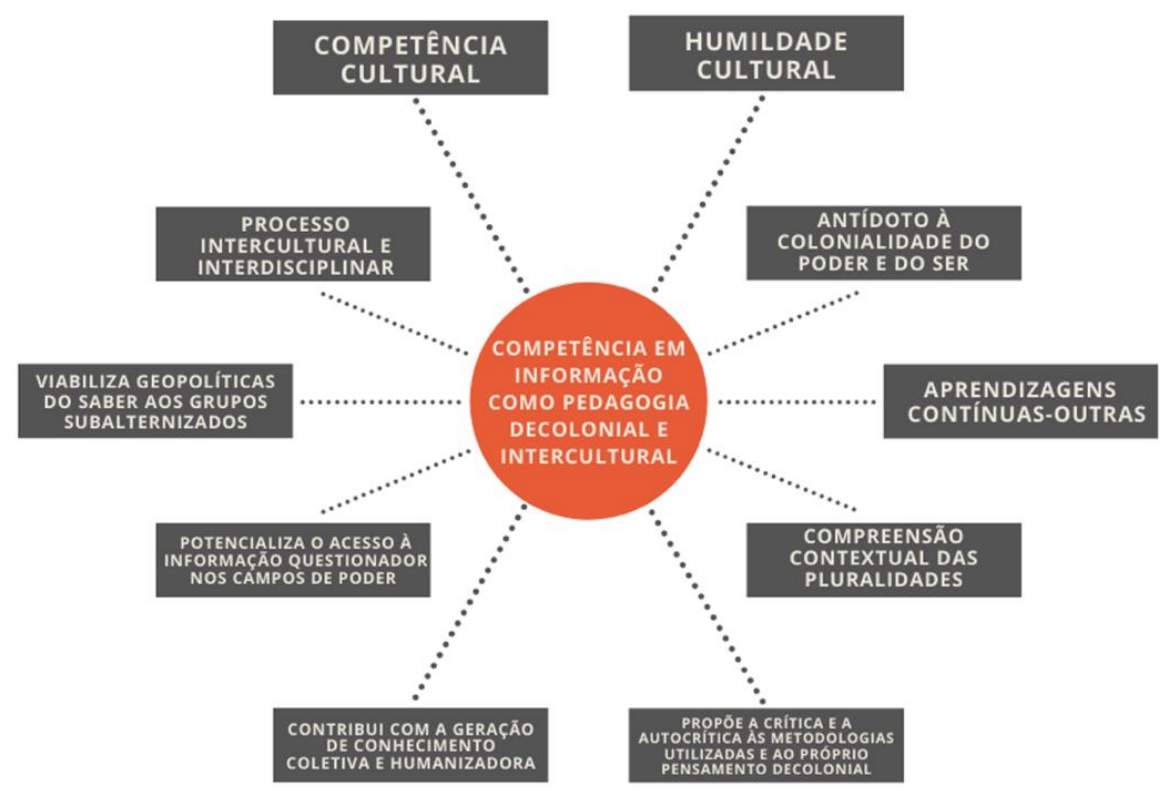

Fonte: Elaborado pelos autores (2021).

Além disso, pode-se considerar que a competência em informação deve se configurar nos mais variados lugares, como, por exemplo, em bibliotecas, instituições de ensino, universidades, bairros, comunidades, residências, na rua, movimentos e organizações. Sendo assim, a competência em informação tal como as pedagogias descoloniais/interculturais, não são utopias (no sentido de algo irrealizável), mas utopísticas. Isto é, a avaliação séria, realista e profunda das melhores alternativas, sendo criativas, originais, novas e plausíveis, proposta como prática simultânea nos campos científico, moral e político (Wallerstein, 2003).

Compreender a competência em informação como utopística constitui um forte subsídio para ultrapassar o medo do novo, das mudanças, da crítica e das alienações hegemônicas das sociedades modernas que ainda reproduzem práticas colonialistas. Diante disso, apresentam-se alguns questionamentos concernentes sobre a competência em informação nesse rol:

- Como a competência é replicada e como é ensinada em instituições educacionais?

- Quais orientações didáticas/técnicas predominam na sua aplicação? 
- Como a geopolítica do conhecimento e as condições institucionais afetam os seus padrões de desenvolvimento e formação?

- Quais são as características das práticas pedagógicas dominantes?

- Como as suas práticas e os seus preceitos são configurados nas instituições educacionais?

- Como se seleciona o conteúdo a ser disseminado?

- Que conteúdo é ensinado? Quem o criou? Quando? Para quê e para quem?

- A partir de qual 'lugar’ ideológico foi configurado o conteúdo a ser ensinado?

- De que forma se configurariam uma outra ciência social aplicada e uma outra pedagogia, que não reproduzam ou subalternizem saberes e subjetividades, mas que seja projetada e se posicione a partir de perspectivas sociais e epistêmicas descoloniais?

Para mais, entende-se que a competência em informação também deve ser conjecturada a partir dos princípios do bem viver, não apenas a partir de critérios teóricos críticos, mas a partir de ações práticas de insurgência educacional que se traduza em processos interculturais. Melhor dizendo, tratam-se das ações, estratégias, metodologias e práticas que se configuram em/por/com/a partir/para a ressignificação, reexistência, resistência e reumanização em oposição à colonialidade do poder, do ensinar, do aprender, do ser e do sentir.

\section{CONSIDERAÇÕES FINAIS}

Pensar a decolonialidade da educação e das aprendizagens contínuas implica levantar e argumentar a emergência e a urgência de uma pedagogia decolonial. Contudo, os desafios são grandes: decolonizar a pedagogia, o currículo, os parâmetros de ensino e a didática por meio da ciência decolonial; decolonizar as epistemologias e as metodologias. É essencial (re)formular métodos decoloniais que permitam configurar currículos, didáticas, aprendizagens, ensinos e avaliações.

Mediante a isso e com base nas reflexões trazidas, se compreende que há uma necessidade crítica, teórica e empírica de desenvolver a competência em informação subversiva, isto é, insurgente frente às necessidades de decolonizar as barreiras sociais, linguísticas, acadêmicas e profissionais das colonialidades existentes nos projetos da modernidade. O artigo buscou delinear os pressupostos considerados 
iniciais para o alargamento da competência em informação como pedagogia decolonial e intercultural, com o objetivo fundante de ratificar seu fazer como fazeresoutros, expandindo as formas de discutir, de ensinar e de assimilar as múltiplas formas possíveis dessa metacompetência.

Deve-se, portanto, assumir a competência em informação como metodologia(s) e ação(es) emergente(s) em contextos de marginalização, subalternização, luta, reexistência e resistência. Assim, tal perspectiva contribui com práticas insurgentes de resistir, (re)existir e (re)viver, que possibilitam modos muito diversos de ser, existir, pensar, conhecer, sentir, ser e conviver - depressa, como práxis fronteiriça que afronta a colonialidade do poder e as suas práticas pedagógicas.

É no diálogo com outros saberes que se abre a perspectiva de uma nova ordem geopolítica de produção de conhecimento. Este, por sua vez, se configura, de forma dinâmica e contínua, em transformação social por meio de pensamentos críticos de fronteira e de posicionamentos que questionam a universalidade neoliberalista do acesso à informação e do conhecimento predominantes. Ter um posicionamento crítico de fronteira significa reconhecer a capacidade de adentrar os espaços sociais, políticos e epistêmicos anteriormente negados e ressignificar esses espaços por meio de formas que respondam à (re)colonização persistente de poder.

\section{FINANCIAMENTO}

Agradecemos à Coordenação de Aperfeiçoamento de Pessoal de Nível Superior (CAPES), pelo financiamento da pesquisa em nível de doutorado do autor principal, possibilitando o desenvolvimento contínuo de pesquisas e estudos como o aqui apresentado.

\section{REFERÊNCIAS}

AGUERO-CONTRERAS, Fernando Carlos; URQUIZA-GARCIA, Cándida Rosa. Multicultura e interculturalidad: implicaciones de una ausencia en la educación. Educ. Pesqui., 2016. vol. 42, no. 2, p. 459-475. [Acesso em 10 maio 2021]. DOI 1590/S15179702201606146327.

AGUER, Bárbara (Ed.), 2014. Cartografías del poder y descolonialidad. Buenos Aires: Del Signo.

AMERICAN LIBRARY ASSOCIATION (ALA). Association of College and Research Libraries (ACRL). Presidential Committee on Information Literacy: Final Report 
(January 1989). [Acesso em 16 maio 2021]. Disponível em: http://www.ala.org/acrl/publications/whitepapers/presidential.

BALLESTRIN, Luciana. América Latina e o giro decolonial. Rev. Bras. Ciênc. Polít., 2013. no. 11, p. 89-117. [Acesso em 23 maio 2021]. DOI 10.1590/S0103-33522013000200004.

CASTRO-GÓMEZ, Santiago, 2005. Ciências sociais, violência epistêmica e o problema da 'invenção do outro'. Em: LANDER, Edgardo (Org.). A colonialidade do saber: eurocentrismo e ciências sociais, perspectivas latino-americanas. Buenos Aires: Clacso.

COOKE, Nicole A, 2017. Information services to diverse populations: Developing culturally competent library professionals. Santa Barbara, CA: Libraries Unlimited.

DANTAS, Sylvia Duarte (Org.), 2012. Diálogos Interculturais: Reflexões Interdisciplinares e Intervenções Psicossociais. São Paulo: Instituto de Estudos Avançados da Universidade de São Paulo.

ELMBORG, James. Critical information literacy: implications for instructional practice. The Journal of Academic Librarianship. 2006. vol. 32, no. 2, p. 192-199. [Acesso em 10 maio 2021]. DOI 10.1016/j.acalib.2005.12.004.

FANON, Frantz, 1968. Sociologia de una revolución. México: Ediciones ERA.

FANON, Frantz, 2008. Pele Negra, Máscaras Brancas. Salvador. Editora: EDUFBA.

FANON, Frantz, 2009. Los Condenados de la Tierra. Buenos Aires: Fondo de Cultura Económica.

FANON, Frantz, 2011. Racismo e cultura. Em: SANCHES, Manuela Ribeiro (Org.). Malhas que os Impérios tecem. Textos anticoloniais, contextos pós-coloniais. Portugal. p. 273-283.

FLICK, Uwe, 2009. Introdução à pesquisa qualitativa. 3. ed. Porto Alegre: Artmed, 2009.

FONTALVO, Iván Manuel Sánchez, 2013. La interculturalidad desde la perspectiva de la inclusión socioeducativa. Santa Marta: Universidad del Magdalena.

FREIRE, Paulo, 1996. Pedagogia da autonomia: saberes necessários à prática educativa. São Paulo: Paz e Terra.

FREIRE, Paulo, 2013. Pedagogia da Tolerância. Rio de Janeiro: Paz e Terra.

FREIRE, Paulo, 2014. Pedagogia dos sonhos possíveis. São Paulo: Paz e Terra.

HICKS, Alison; LLOYD, Annemaree. It takes a community to build a framework: Information literacy within intercultural settings. Journal of Information Science. 2016. vol. 42, no. 3, p. 334-343. [Acesso em 30 abril 2021]. DOI 10.1177/0165551510000000

JACOBS, Heidi L. M. Information literacy and reflective pedagogical praxis. The Journal of Academic Librarianship, v. 34, n. 3, p. 256-262, 2008. [Acesso em 15 maio 2021]. DOI 10.1016/j.acalib.2008.03.009. 
LATOUR, Bruno, 2004. Políticas da natureza: como fazer ciência na democracia. Bauru: Edusc, 2004.

LLOYD, Annemaree. Information literacy: the meta-competency of the knowledge economy? An exploration paper. Journal of Librarianship and Information Science. 2003. vol. 35, no. 2, p. 87-92. [Acesso em 10 maio 2021]. DOI $10.1177 / 0961000603352003$.

LLOYD, Annemaree. Information literacy landcapes: an emerging picture. Journal of Documentation. 2006. vol. 62, no. 5, p. 570-583. [Acesso em 16 maio 2021]. DOI $10.1108 / 00220410610688723$.

LUYT, Brendan; AZURA, Intan. The sigh of the information literate: an examination of the potential for oppression in information literacy. Information Research. 2010. vol. 15, no. 3. [Acesso em 15 maio 2021]. Disponível em: http://informationr.net/ir/153/colis7/colis711.html.

MIGLIEVICH-RIBEIRO, Adelia. Por uma razão decolonial: Desafios ético-políticoepistemológicos à cosmovisão moderna. Civitas - Revista de Ciências Sociais. 2014. 14, n. 1, p. 66-80. [Acesso em 15 maio 2021]. DOI 10.15448/1984-7289.2014.1.16181.

MIGNOLO, Walter, 2013. Historias locales/diseños globales: colonialidad, conocimientos subalternos y pensamiento fronterizo. Madrid: Akal, 2013.

MIGNOLO, Walter, 2007. El pensamiento decolonial: despredimiento y apertura. Em: CASTRO-GÓMES, Santiago; GROSFOGUEL, Ramón. El giro decolonial: reflexiones para una diversidad epistémica más allá del capitalismo global. Bogotá: Siglo del Hombre editores; Universidade Central; Instituto de Estudios Socialies Contemporáneos y Pontificia Universidad Javeriana; Instituto Pensar. p. 25-47.

MIGNOLO, Walter, 2010. Desobediencia epistémica: retórica de la modernidad, lógica de la colonialidad y gramática de la descolonialidad. Buenos Aires: Ediciones del Signo.

MIGNOLO, Walter, 2011. The darker side of western modernity: global futures, decolonial options. Durham: Duke University Press.

MINAYO, Maria Cecília de Souza (Org.), 2011. Pesquisa social: teoria, método e criatividade. 18. ed. Petrópolis: Vozes.

MOREIRA, Antônio Flávio Barbosa; CANDAU, Vera Maria, 2007. Indagações sobre currículo: currículo, conhecimento e cultura. Brasília: Ministério da Educação, Secretaria de Educação Básica.

OCAÑA, Alexander Ortiz, 2016. Epistemologías de la modernidad. Cambio de paradigma en el siglo XXI. Bogotá: Klasse.

OCAÑA, Alexander Ortiz; LÓPEZ, María Isabel Arias; CONEDO, Zaira Esther Pedrozo, 2018. Decolonialidad de la educación: emergencia urgencia de una pedagogía decolonial. Santa Marta: Universidad del Magdalena.

OLIVEIRA, Luiz Fernandes de; CANDAU, Vera Maria Ferrão. Pedagogia decolonial e educação antirracista e intercultural no Brasil. Educ. rev., 2010. vol. 26, no. 1, p. 15-40. [Acesso em 25 abril 2021]. DOI 10.1590/S0102-46982010000100002. 
QUIJANO, Aníbal. Colonialidad del poder, eurocentrismo y América Latina, 2005. Em: LANDER, E. (Org.). La colonialidad del saber: eurocentrismo y ciencias sociales. Perspectivas Latinoamericanas. Buenos Aires: Clacso. p. 227-277.

QUIJANO, Aníbal. Colonialidad del poder y clasificación social, 2007. Em: CASTROGÓMEZ, S.; GROSFOGUEL, R. (Orgs.). El giro decolonial. Reflexiones para una diversidad epistémica más allá del capitalismo global. Bogotá: Universidad JaverianaInstituto Pensar, Universidad Central-IESCO, Siglo del Hombre Editores. p. 93-126.

QUIJANO, Aníbal. Colonialidade do poder e classificação social, 2009. Em: SANTOS, Boaventura de Sousa; MENESES, Maria Paula (Orgs.). Epistemologias do Sul. Coimbra Portugal: Almedina. p. 74-117.

QUIJANO, Aníbal (Ed.), 2014. Des/colonialidad y bien vivir: un nuevo debate en America Latina. Lima: Editorial Universitaria.

SANTOS, Boaventura de Sousa. El Foro Social Mundial y la Izquierda Global. El Viejo Topo. 2008. vol. 240, p. 39-62. [Acesso em 15 maio 2021]. Disponível em: https://www.ces.uc.pt/bss/documentos/el_foro_social_mundial_y_la_izquierda_glob al_2008.pdf.

SANTOS, Boaventura de Sousa; MENESES, Maria Paula. (Orgs.), 2009. Epistemologias do Sul. Coimbra: Edições Almedina.

SANTOS, Boaventura de Sousa, 2010. Descolonizar el Saber, Reinventar el Poder. Montevideo: TRILCE.

SCHIFFMAN, Leon G.; KANUK, Leslie Lazar, 2000. Comportamento do consumidor. 6. ed. Rio de Janeiro: LTC.

SEGATO, Rita Laura, 2014. Aníbal Quijano y la perspectiva de la colonailidad del poder. Em: QUIJANO, Aníbal (Ed.). Des/colonialidad y bien vivir: un nuevo debate en America Latina. Lima: Editorial Universitaria. p. 35-71.

RIGHETTO, Guilherme Goulart; VITORINO, Elizete Vieira; MURIEL-TORRADO, Enrique. Competência em informação no contexto da vulnerabilidade social: conexões possíveis. Informação \& Sociedade: Estudos. 2018. vol. 28, no. 1. [Acesso em 30 abril 2021]. Disponível em: https://periodicos.ufpb.br/ojs2/index.php/ies/article/view/34735.

SOFIA, Pasquale, 2013. La descolonización cultural de América Latina. Antología de una polémica filosófica. Maracaibo: Universidad Católica Cecilio Acosta.

SPIVAK, Gayatri Chakravorty, 2010. Pode o subalterno falar? Belo Horizonte: Editora UFMG.

SPIVAK, Gayatri Chakravorty, 2015. Crítica de la razón poscolonial. Hacia una historia del presente evanescente. Madrid: Akal.

SUESS, Rodrigo Capelle; SILVA, Alcinéia de Souza. A perspectiva decolonial e a (re)leitura dos conceitos geográficos no ensino de geografia. Geografia Ensino \& Pesquisa. 2019. v. 23, n. 7. [Acesso em 25 abril 2021]. DOI 10.5902/2236499435469.

TERVALON, Melanie; MURRAY-GARCIA, Jann. Cultural humility versus cultural competence: A critical distinction in defining physician training outcomes in 
multicultural education. Journal of Health Care for the Poor and Undeserved. 1998. vol. 9, p. 117-125. [Acesso em 25 abril 2021]. DOI 10.1353/hpu.2010.0233.

VITORINO, Elizete Vieira; PIANTOLA, Daniela, 2020. Competência em informação: conceito, contexto histórico e olhares. Florianópolis: Editora da UFSC.

WALLERSTEIN, Immanuel, 2003. Utopística o las opciones históricas del Siglo XXI. México: Siglo XXI.

WALSH, Catherine, 2001. La educación intercultural en la educación. Peru: Ministerio de Educación.

WALSH, Catherine, 2005. Introducion - (Re) pensamiento crítico y (de) colonialidad. Em: WALSH, C. Pensamiento crítico y matriz (de)colonial. Reflexiones latinoamericanas. Quito: Ediciones Abya-yala. p. 13-35.

WALSH, Catherine, 2006. Interculturalidad y colonialidad del poder. Un pensamiento y posicionamiento 'otro' desde la diferencia colonial. Em: WALSH, C.; LINERA, A. G.; MIGNOLO, W. Interculturalidad, descolonización del estado y del conocimiento. Buenos Aires: Del Signo. p. 21-70.

WALSH, Catherine, 2007. Interculturalidad Crítica/Pedagogia decolonial. Em: Memórias del Seminário Internacional "Diversidad, Interculturalidad y Construcción de Ciudad”. Bogotá: Universidad Pedagógica Nacional.

WALSH, Catherine. Interculturalidad y (de)colonialidad: Perspectivas críticas y políticas. Visão Global. 2012. vol. 15, no. 1-2, p. 61-74. [Acesso em 15 maio 2021]. Disponível em: https://portalperiodicos.unoesc.edu.br/visaoglobal/article/view/3412.

TRINIDAD PÉREZ, Arias, 2012 La construcción del campo moderno del arte en el Ecuador, 1860-1925: Geopolíticas del Arte y Eurocentrismo [em linha]. Tesis (Doctorado en Estudios Culturales Latinoamericanos). Ecuador: Universidad Andina Simón Bolívar. [Acesso em 25 abril 2021]. Disponível em: https://repositorio.uasb.edu.ec/bitstream/10644/3081/1/TD028-DECLA-PerezLa\%2oconstruccion.pdf.

WALSH, Catherine, 2014. Lo pedagógico y lo decolonial: entretejiendo caminos. Quito: Qurétaro.

WALSH, Catherine, 2017. Pedagogías Decoloniales. Prácticas insurgentes de resistir, (re) existir y (re)vivir. Tomo II. Quito: Abya-Yala.

ZIBECHI, Raúl, 2015. Descolonizar el pensamiento crítico y las prácticas emancipatorias. Bogotá: Ediciones desde abajo. 